INRA Prod. Anim., 2010, 23 (2), 143-154

\title{
Structure, propriétés et minéralisation de la coquille de l'œuf: rôle de la matrice organique dans le contrôle de sa fabrication
}

\author{
Y. NYS', M.-T. HINCKE', A. HERNANDEZ-HERNANDEZ ${ }^{3}$, A.-B. RODRIGUEZ-NAVARRO4, \\ J. GOMEZ-MORALES ${ }^{3}$, V. JONCHËRE', J.-M. GARCIA-RUIZ ${ }^{3}$, J. GAUTRON ${ }^{1}$ \\ ${ }^{1}$ INRA, UR83 Recherches Avicoles, F-37380 Nouzilly, France \\ ${ }^{2}$ Cellular and Molecular Medicine, University of Ottawa, Ottawa, Canada K1H 8M5 \\ ${ }^{3}$ IACT (CSIC-UGRA). Avda. Conocimiento, s/n. P.T., 18100. Armilla, Granada, Espagne \\ ${ }^{4}$ Universidad de Granada. Campus Fuentenueva, s/n 18002 Granada, Espagne
}

Courriel : Yves.Nys@tours.inra.fr

L'ultrastructure de la coquille de l'œuf et ses propriétés mécaniques remarquables ont été révélées dès les années 70. Mais ce n'est que depuis 15 ans qu'ont été décryptées les interactions existant entre les constituants de la matrice organique et les cristaux minéraux de la coquille, interactions qui contrôlent l'ultrastructure et la texture cristalline de ce biomatériau et en déterminent les propriétés mécaniques.

La coquille de l'œuf est une structure parfaitement définie, adaptée aux diverses fonctions indispensables pour assurer la reproduction des oiseaux dans un milieu extérieur. Son premier rôle est de protéger le contenu de l'œuf de l'environnement physique et microbien, le second de permettre les échanges d'eau et de gaz au travers de pores pour assurer le développement extra-utérin de l'embryon et le troisième de fournir le calcium pour assurer la calcification osseuse de ce même embryon. La constitution de la coquille répond à ces besoins : c'est en effet une céramique poreuse rigide. Elle est suffisamment solide pour assurer une protection contre les prédateurs au cours du développement embryonnaire, mais deviendra assez fragile pour permettre l'éclosion du poussin. Cette coquille se forme à basse température $\left(40^{\circ} \mathrm{C}\right)$ en moins de $24 \mathrm{~h}$; elle fait donc appel à l'un des processus de minéralisation les plus rapides du monde vivant. Cette céramique cristalline présente des propriétés mécaniques remarquables résultant d'une longue évolution : une coquille de $0,3 \mathrm{~mm}$ résiste à trois kilos en pression statique. Toutes les coquilles sont constituées du même matériel minéral, la calcite, qui est la forme trigonale du carbonate de calcium la plus stable à température ambiante. Elle se construit en quelques heures dans un espace confiné, la partie distale de l'oviducte (cf. encadré 1, Travel et al 2010), dans un milieu acellulaire. Ce fluide utérin est saturé vis-à-vis du calcium et des bicarbonates, et contient les précurseurs minéraux et organiques de la coquille, secrétés par l'isthme et l'utérus. Les propriétés qui distinguent la coquille d'œuf de l'os ou de la dent sont la nature du dépôt minéral, le carbonate de calcium, et l'absence de cellule dans le milieu de minéralisation. Une autre particularité est son autoformation sur membranes, dirigée par la présence en leur surface externe de sites organiques de nucléation. L'épaisseur de coquille, sa forme, sa taille, sa porosité, sa microstructure fluctuent selon les espèces aviaires ; cependant, sa structure globale et sa formation sont similaires chez tous les oiseaux. L'objet de cette revue est de décrire la coquille et sa composition, l'origine de ses constituants et d'expliquer sa formation et l'origine de

Figure 1. Vue en microscopie électronique à balayage d'une coupe transversale de coquille d'œuf de poule (vue générale à gauche) montrant, de bas en haut (détails à droite), les fibres des membranes coquillières, l'ancrage d'un cône et la cuticule en surface (Nys et al 2001).

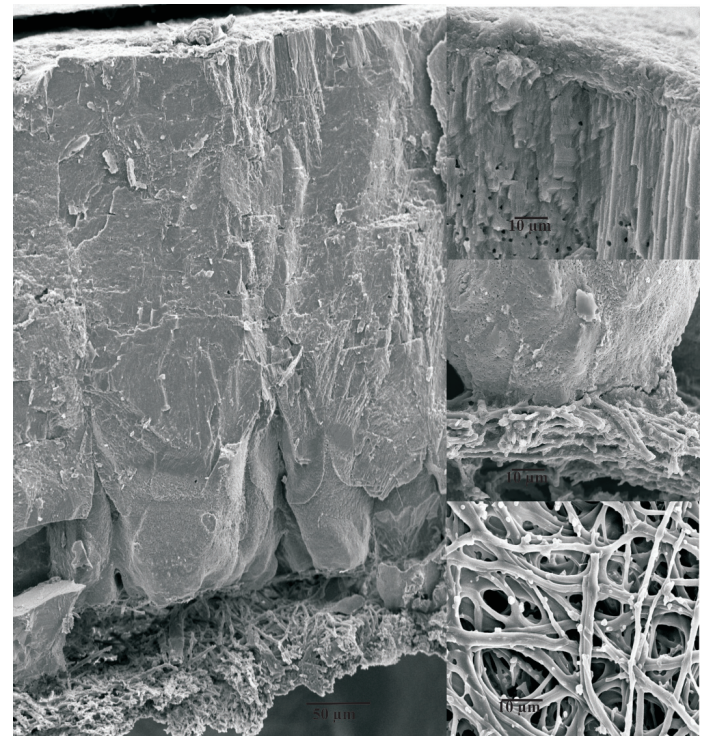


Figure 2. Représentation schématique d'une coupe transversale de la coquille.

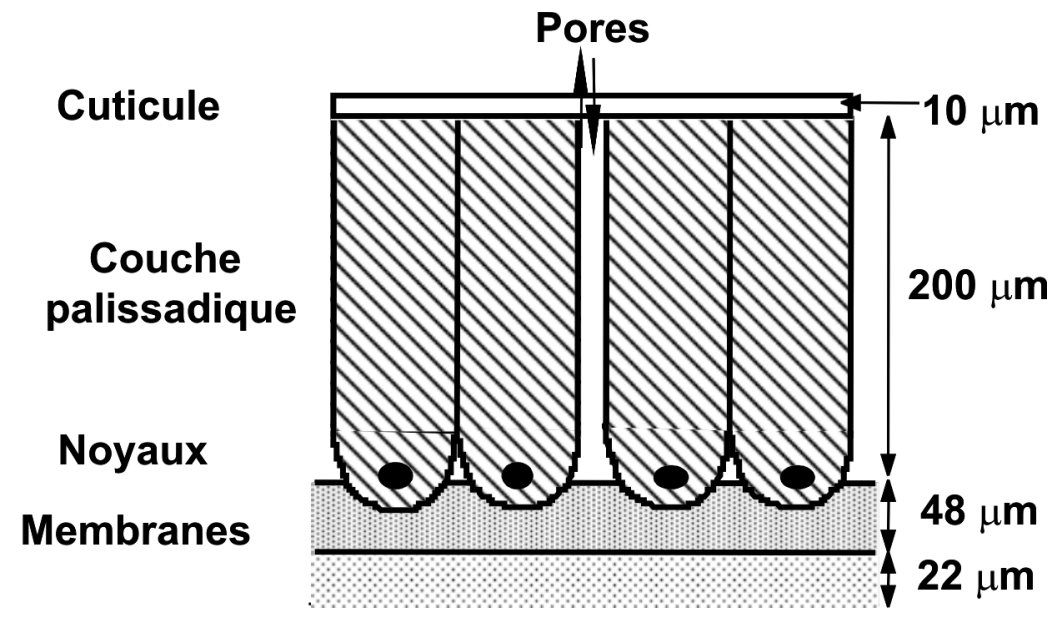

Figure 3. Vue en lumière polarisée d'une coupe transversale de coquille de pintade et de dinde montrant les colonnes cristallines adjacentes et la couche de cristaux verticaux en surface (Garcia-Ruiz J., communication personnelle).

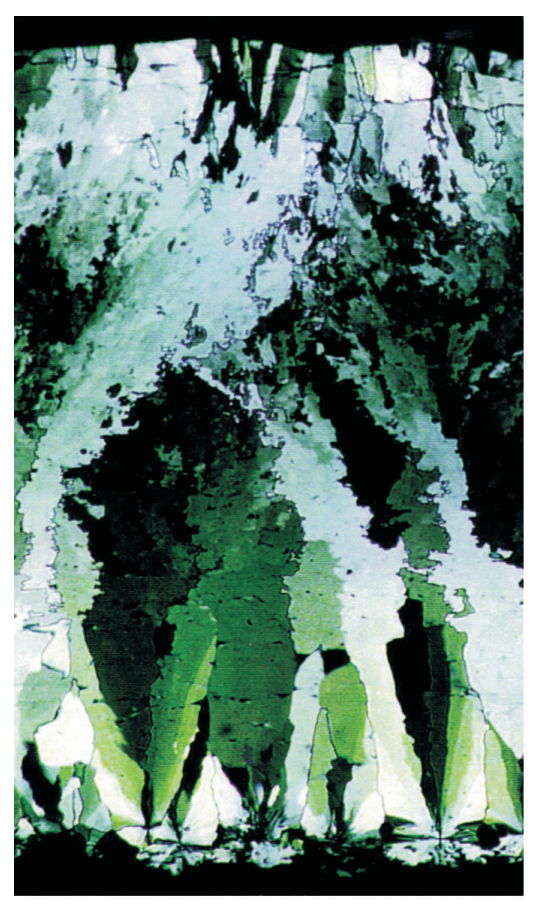

Pintade

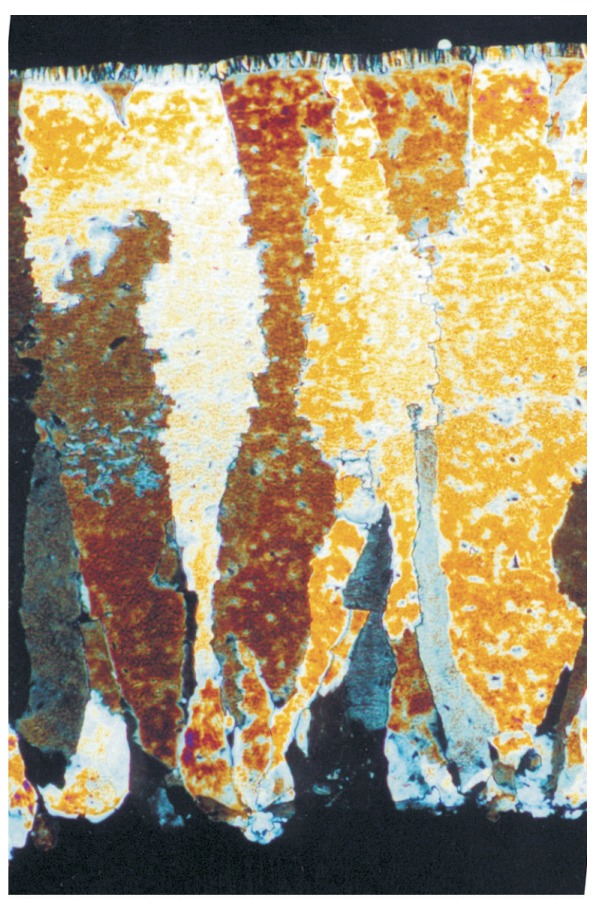

Dinde
Figure 4. Vue d'un pore en formation (microscopie électronique à balayage) en surface d'une coquille en formation (Solomon 1991).

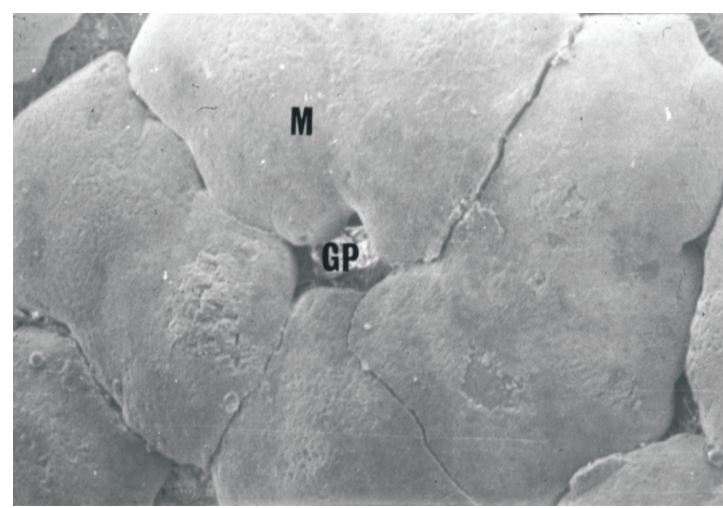

sa structure sophistiquée responsable de ses propriétés mécaniques exceptionnelles.

\section{1 / Structure de la coquille}

La structure de la coquille est similaire chez les différentes espèces d'oiseaux et a été décrite par de nombreux auteurs (Tyler 1964, Sauveur 1988, Solomon 1991, Nys et al 1999). L'observation au microscope électronique à balayage (figure 1) permet de distinguer 5 couches dont une schématisation est présentée en figure 2. La partie interne de la coquille correspond aux deux membranes coquillières constituées de fibres protéiques entrelacées qui limitent la diffusion du blanc. La partie minérale est ancrée en surface de la membrane externe. La croissance des cristaux à partir de sites de nucléation ou noyaux mamillaires, est à l'origine des cônes inversés qui se rejoignent pour former la couche palissadique compacte. Cette couche de $200 \mu \mathrm{m}$ chez la poule est composée de colonnes irrégulières, juxtaposées dont le diamètre varie de 10 à $30 \mu \mathrm{m}$. Elle est composée de cristaux rhomboédriques de calcite couverts en superficie d'une couche de cristaux verticaux, perpendiculaires à la surface de la coquille (figure 3). Une cuticule, d'une épaisseur de $10 \mu \mathrm{m}$, couvre l'ensemble de la coquille, y compris les pores. Elle limite les pertes en eau de l'œuf et la pénétration bactérienne. La coquille d'un œuf est traversée d'environ 10000 pores (figure 4).

La quantité de matériau, corrélée à l'épaisseur de la coquille, est le facteur prépondérant de la qualité de la coquille. Sa proportion $(10-11 \% \mathrm{du}$ poids de l'œuf) est relativement stable quelle que soit la taille de l'œuf, d'un poids pouvant aller de 0,5 g pour l'œuf de colibri à $1,9 \mathrm{~kg}$ pour l'œuf d'autruche. Le mode d'organisation des cristaux de calcite influence également ses propriétés mécaniques. Sa solidité diminue quand l'épaisseur de la coquille est plus faible, mais également lorsque les cristaux de calcite s'orientent selon une direction privilégiée, car le nombre de plans de clivage croît alors dans le matériau. La microstructure de la coquille est parfaitement définie. C'est une céramique polycristalline constituée de carbonate de calcium d'un seul polymorphe, la calcite. Au début de la formation de la coquille, les cristaux de calcite sont de petite taille et déposés sans orientation privilégiée. Dans la couche palissadique les cristaux augmentent leur taille au fur et à mesure du dépôt et présentent une élongation selon l'axe $\mathrm{C}$ de la calcite. Cette structure cristalline est révélée par la microscopie optique en lumière polarisée montrant 
Figure 5. Microphotographies en lumière polarisée de coquille d'autruche (A), pintade (C) et poule (E).

La barre d'échelle correspond à $100 \mu \mathrm{m}$. Chaque colonne cristalline présente un coefficient d'extinction de la lumière en fonction de son orientation cristalline. A droite est présenté un spectre de diffraction aux rayons $X$ des mêmes coquilles. La coquille d'autruche présente une concentration d'anneaux courts révélant des orientations préférentielles marquées. Au contraire, pour la pintade, les anneaux sont continus démontrant des orientations cristallines aléatoires. Cette absence de direction privilégiée favorise la solidité du matériel en réduisant la probabilité d'apparition de plans de clivage (Rodriguez-Navarro et Romanek 2002).
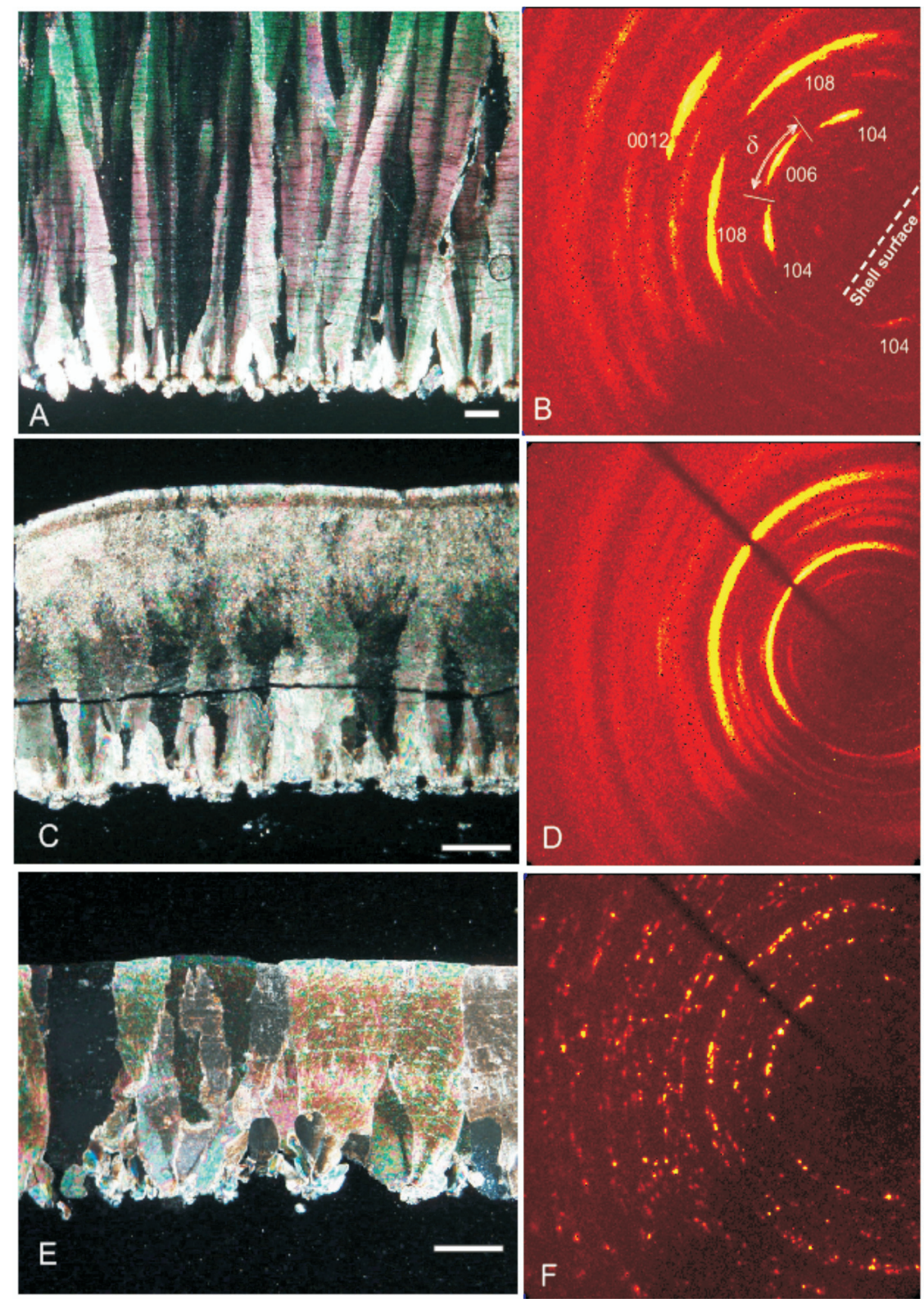

Tableau 1. Les différentes protéines identifiées dans la matrice organique de l'œuf de poule.

\begin{tabular}{|c|c|c|}
\hline $\begin{array}{l}\text { Protéines initialement } \\
\text { identifiées dans } \\
\text { le blanc d'œuf }\end{array}$ & $\begin{array}{l}\text { Protéines } \\
\text { ubiquitaires }\end{array}$ & $\begin{array}{l}\text { Protéines } \\
\text { spécifiques }\end{array}$ \\
\hline $\begin{array}{c}\text { Ovalbumine } \\
\text { Lysozyme } \\
\text { Ovotransferrine }\end{array}$ & $\begin{array}{l}\text { Ostéopontine } \\
\text { Clustérine }\end{array}$ & $\begin{array}{l}\text { Ovocléidine-17 } \\
\text { Ovocléidine-116 } \\
\text { Ovocalyxine-36 } \\
\text { Ovocalyxine-32 } \\
\text { Ovocalyxine-25 } \\
\text { Ovocalyxine-21 }\end{array}$ \\
\hline
\end{tabular}

des coupes transversales de coquilles des cristaux s'oriente progressivement selon une direction privilégiée pour la plupart des espèces à l'exception de la pintade, du canard ou de l'oie. L'axe C de la calcite tend à être perpendiculaire à la surface de la coquille dans son tiers supérieur (poule, caille, faisan, dindon, autruche).

\section{2 / Composition de la coquille}

La coquille de l'œuf d'oiseau et les membranes coquillières qui la supportent renferment en moyenne $1,6 \%$ d'eau, 3,3 à 3,5\% de matière organique et $95 \%$ de matière minérale. La coquille elle-même (sans sa cuticule) est composée majoritairement de carbonate de calcium $(94 \%)$ et d'une faible proportion de constituants organiques $(2,3 \%)$ inclus dans la partie minéralisée. Elle contient $37,5 \%$ de calcium et $58 \%$ de carbonate mais également du magnésium et du phosphore, ce dernier étant concentré dans les couches superficielles. Elle contient enfin de nombreux oligoéléments dont du manganèse (7 mg. $\mathrm{kg}^{-1}$ ) dont l'apport alimentaire chez la poule favorise la solidité de la coquille probablement en influençant sa structure cristalline.

Les membranes coquillières sont constituées de fibres composées majoritairement d'une protéine fibreuse spécifique à la coquille mais possédant des pontages proches de ceux observés dans le collagène (Chowdhury 1990, Nys et al 1999). Les membranes contiennent également du collagène de types I et X. En surface de la membrane externe, les noyaux mamillaires sont riches en protéoglycanes à kératane sulfate. Ces noyaux correspondent aux sites de nucléation des premiers cristaux de calcite (Fernandez et al 1997). Une altération pharmacologique de la synthèse des fibres des membranes coquillières (Chowdhury 1990), perturbe considérablement l'organisation structurale de la coquille, démontrant le rôle essentiel de ces membranes dans le processus de minéralisation de la coquille et le contrôle de sa microstructure.

Les couches calcifiées de la coquille contiennent une matrice organique constituée à $70 \%$ de protéines et de polysaccharides sulfatés. Les protéines de la matrice organique peuvent être classées en 3 familles (tableau 1 ; Nys et al 2004, Gautron et Nys 2010).

Certaines protéines, préalablement décrites dans le blanc d'œuf (ovotransferrine, ovalbumine, lysozyme), sont obser- 
Figure 6. Cinétique de formation de la coquille.

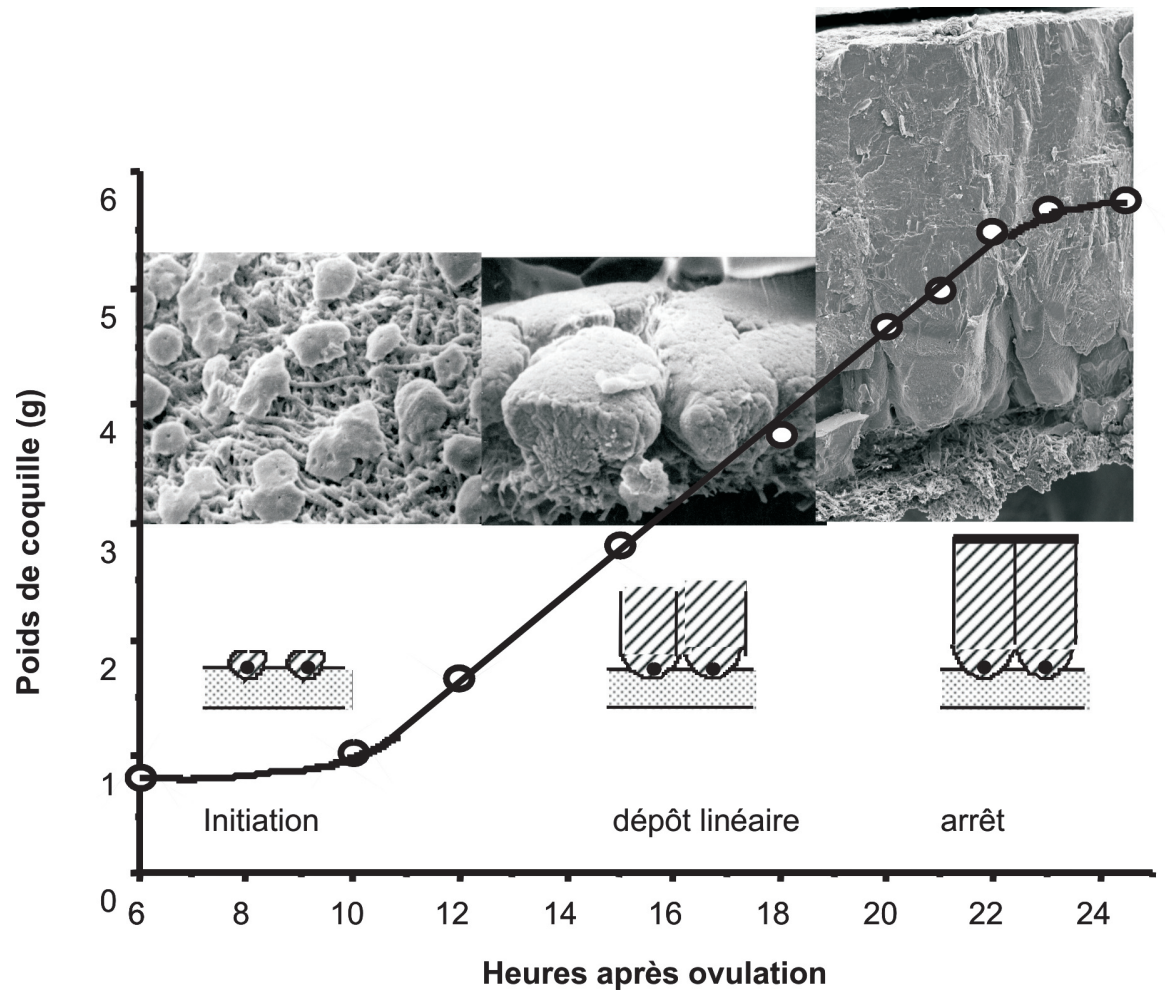

vées dans les membranes coquillières et la coquille, essentiellement dans sa partie basale (Hincke 1995, Hincke et al 2000, Gautron et al 2001a). Des protéines ubiquitaires sont également retrouvées dans la coquille. Une phosphoprotéine noncollagénique de l'os, l'ostéopontine, est présente dans la couche calcifiée et le fluide utérin (Pines et al 1994) et présente une surexpression de son ARNm lors de la calcification de la coquille induite par la dilatation de l'utérus provoquée par la pénétration de l'œuf (Lavelin et al 1998). Elle inhibe la précipitation du carbonate de calcium et pourrait moduler celle-ci dans le fluide utérin. La clustérine (Mann et al 2003) est une protéine extracellulaire présente dans la coquille et les membranes coquillières qui agirait comme protéine chaperonne, en empêchant la précipitation prématurée des composants de la matrice organique dans le fluide utérin.

La dernière famille regroupe des protéines spécifiques de la coquille des oiseaux, synthétisées uniquement par l'isthme ou l'utérus, où se forme la coquille. L'ovocléidine 17 (OC17) est la protéine la plus abondante, synthétisée par les cellules tubulaires de l'utérus (Hincke et al 1995). Elle est présente dans les noyaux mamillaires et dans l'ensemble de la couche minéralisée. Elle pourrait agir comme protéine de structure dans l'assemblage du réseau matriciel. De nombreuses protéines ayant des similarités avec l'OC17 (domaine de type lectine C) ont été observées chez l'oie, l'autruche mais aussi chez l'émeu et le nandou (Lakshminarayanan et al 2002, Mann 2004, Mann et Siedler 2004, 2006). L'ovocléidine 116, strictement utérine, est sécrétée par les cellules épithéliales (Hincke et al 1999). Elle est révélée dans la couche palissadique et matéique d'un protéoglycane riche en dermatane sulfate préalablement décrit par Carrino et al (1997). Ce composé est soupçonné d'interférer fortement avec les cristaux de calcite du fait de sa charge négative. Enfin, différentes ovocalyxines ont été identifiées par des approches moléculaires (Gautron et Nys 2007). Ces protéines sont synthétisées par l'utérus, sécrétées dans le fluide utérin et sont présentes dans les extraits de coquille. L'ovocalyxine 32 est synthétisée par les cellules épithéliales de l'utérus au stade terminal de la calcification; elle est présente en surface de la coquille et pourrait donc être associée à l'arrêt de la calcification (Gautron et al 2001b).

L'ovocalyxine 36 est synthétisée par les glandes tubulaires. Son expression est fortement stimulée lors de la présence d'un œuf in utéro. De nombreux arguments (identité partielle de la séquence protéique, analogie des motifs fonctionnels, architecture des gènes, localisation sur le chromosome 20) suggèrent une origine commune pour l'ovocalyxine 36 , les protéines mammaliennes liant les lipides (LBP, mammalian lipid-binding proteins) et les protéines bactéricides augmentant la millaire. Elle correspond au cœur pro- perméabilité membranaire (BPI, bactericidal permeability-increasing proteins) (Gautron et al 2007). Ces protéines du système immunitaire inné sont impliquées dans la défense précoce contre les agresseurs bactériens. L'ovocalyxine 36 aurait donc un rôle de protection chimique de l'œuf en formation dans le fluide utérin. L'ovocalyxine 21, sécrétée principalement pendant la phase active de calcification, se caractérise par la présence d'un domaine appelé Brichos qui est caractéristique de protéines chaperonnes dont la fonction est d'assister d'autres protéines dans leur maturation en leur assurant un repliement tridimensionnel adéquat (Gautron et Nys 2007). L'ovocalyxine 25 se caractérise par la présence de deux domaines observés de la famille des protéines inhibitrices de protéases à sérine (Gautron et Nys 2010). Il s'agit d'un domaine de type WAP présent dans la lustrine $\mathrm{A}$, qui est une protéine de la couche nacrée des coquilles et des perles produites par les mollusques (Shen et al 1997), et d'un domaine Kunitz. Les ovocalyxines présentent donc de multiples fonctions et pourraient être impliquées dans le contrôle de la minéralisation puisque le fluide utérin qui contient ces protéines modifie in vitro le polymorphisme des cristaux, leur taille et leur morphologie (Gautron et al 1997, Dominguez-Vera et al 2000, Hernandez-Hernandez et al 2008a et c).

Cette caractérisation de la matrice n'est que partielle puisque des études récentes de protéomique (Mann et al 2006, 2007) et transcriptomique (Gautron et Nys 2010, Jonchère et al 2010a) révèlent plusieurs centaines de constituants $(>500)$ dont la fonction reste à déterminer.

La cuticule organique présente en surface de la coquille se compose de $3 \%$ de minéraux, de $5 \%$ de sucres et de plus de $90 \%$ de protéines et glycoprotéines. Elle contient une couche d'hydroxyapatite (Dennis et al 1996) et, dans le cas des coquilles colorées, près des deux tiers des pigments bruns (protoporphyrines) (Nys et al 1991).

\section{3 / Formation de la coquille}

\section{1 / Lieu et chronologie de la formation}

Le point de départ de l'élaboration de toute coquille d'oiseaux est la formation des membranes coquillières. Les fibres des membranes coquillières sont synthétisées puis sécrétées par les glandes tubulaires de l'isthme (Sauveur 1988, Nys et al 1999). Les constituants organiques des sites de nucléation (noyaux mamillaires) sont déposés en surface de 
Encadré 1. Modifications du métabolisme calcique liées à la formation de la coquille

La formation de la coquille est un défi à l'homéostasie calcique de la poule, du fait de la discontinuité du processus journalier et de l'ampleur de l'exportation de calcium : plus de $2 \mathrm{~g} / \mathrm{jour}$, soit $10 \%$ du calcium corporel total. II y a désynchronisation entre la période de formation de la coquille nocturne et la consommation de calcium (cf. revues de Sauveur 1988, Nys 2010). La poule amplifie l'approvisionnement en calcium lors de l'entrée en production, en développant un appétit spécifique pour le calcium. Si la poule dispose en libre choix d'une source de calcium sous forme de particules, elle majore fortement sa consommation de calcium $4 \mathrm{~h}$ avant l'extinction de la lumière ce qui coïncide avec le début de la formation de la coquille (Mongin et Sauveur 1979). Cette capacité est valorisée pour améliorer la solidité de la coquille par l'apport de calcium particulaire (Guinotte et Nys 1993). De plus, les augmentations de la sécrétion acide et de l'eau du proventricule induites par la dilatation du jabot, accroissent la solubilité du carbonate de calcium ingéré et sont à l'origine du doublement de la rétention calcique intestinale observée pendant la calcification de la coquille. L'adaptation à la forte demande en calcium pour la formation de la coquille s'exprime aussi sur un plus long terme. La capacité d'absorption du calcium est en effet multipliée par 6 lors de la maturité sexuelle, suite à l'accroissement considérable de la production rénale du métabolite actif de la vitamine $D$, le 1,25-dihydroxycholécalciférol $\left(1,25(\mathrm{OH})_{2} \mathrm{D}_{3}\right)$ qui contrôle cette capacité (Nys 1993, Bar 2008). Ces adaptations à long et court terme mettent donc en jeu des processus différents. La régulation à long terme est contrôlée par la vitamine $\mathrm{D}$, alors que la fluctuation quotidienne dépend de processus digestifs. Le $1,25(\mathrm{OH})_{2} \mathrm{D}_{3}$ est précisément régulé au niveau rénal par la parathormone et stimule, via les récepteurs de la vitamine $D$, la synthèse de protéines spécifiques dans les organes cibles de la vitamine D (intestin, os et rein). II induit la transcription de gènes codant des protéines impliquées dans le transfert de $\mathrm{Ca}^{++}$, l'expression la mieux caractérisée étant celle de la calbindine. La concentration de cette protéine dans l'épithélium intestinal ou utérin reflète sa capacité à transférer le calcium : au niveau intestinal, elle augmente lors de la maturité sexuelle, puis lors de la formation du premier œuf. Le retrait de la vitamine D de l'aliment diminue considérablement sa teneur intestinale chez des cailles ou des poules. II en est de même lors d'un arrêt de production (Nys 1993, Bar 2008).

la membrane coquillière externe, dans la partie distale de l'isthme. L'œuf fripé, entouré de ses membranes, migre alors dans l'utérus où se poursuit l'hydratation des protéines de l'albumen et où, parallèlement, est initiée la calcification de la coquille. Cet organe est le siège d'une sécrétion abondante de bicarbonate et de calcium et de l'ensemble des précurseurs organiques de la matrice organique de la coquille. La formation de la partie minérale de la coquille est l'étape la plus longue de la formation de l'œuf dans l'oviducte, puisqu'elle dure près de $20 \mathrm{~h}$ (phase de nucléation incluse) sur un total d'environ $24 \mathrm{~h}$. Elle est initiée $4 \mathrm{~h} 30$ après l'ovulation et se termine $1 \mathrm{~h} 30$ avant l'expulsion de l'œuf. Elle se déroule en trois phases (figure 6).

La 1 ère phase, d'environ $5 \mathrm{~h}$, correspond à l'initiation de la minéralisation. Les premiers cristaux de calcite se déposent sur les amas organiques présents en surface des membranes coquillières externes de l'œuf mou dilaté par l'hydratation de l'albumen. La $2^{\text {ème }}$ phase est celle d'une croissance rapide du polycristal, pendant laquelle un dépôt linéaire de $0,33 \mathrm{~g} / \mathrm{h}$ de carbonate de calcium est déposé de $10 \mathrm{~h}$ après l'ovulation à $1 \mathrm{~h} 30$ avant l'expulsion de l'œuf. La dernière phase est l'arrêt de la minéralisation caractérisé par un processus d'inhibition de la minéralisation. La durée de formation de la coquille ne varie pas avec l'âge de la poule, alors que l'intervalle entre deux ovipositions s'accroît notablement avec celui-ci. En revanche, cette durée de minéralisation (et par conséquent le poids de coquille) augmente lorsque les poules sont soumises à un éclairement continu ou à des rythmes ahéméraux supérieurs à 24 h (Sauveur 1996).

La durée de la formation de la coquille est régulée en amont de l'uté- rus. La présence de l'œuf et la dilatation de l'oviducte due à la présence de l'œuf en rotation ne suffisent pas en effet à provoquer la sécrétion des constituants de la coquille par l'utérus. Cette capacité sécrétoire est acquise journellement pendant une durée prédéterminée, synchronisée avec l'ovulation, probablement sous l'effet d'un facteur ovarien issu du follicule rompu, mais de nature indéterminée. L'arrêt de la calcification précède l'expulsion de l'œuf. Le maintien artificiel de l'œuf dans l'utérus, par blocage mécanique de l'oviposition, n'augmente pas la quantité de coquille déposée, contrairement à une prolongation de l'œuf dans l'utérus induite par un traitement ponctuel stéroïdien qui retarde l'ovulation du jaune en inter- férant avec le plus gros follicule ovarien. L'arrêt de la calcification est donc contrôlé par l'ovaire qui induirait la sécrétion par l'utérus en fin de calcification d'inhibiteurs de la minéralisation de la coquille.

\section{2 / Minéralisation de la coquille}

La coquille de l'œuf est assimilable à une céramique industrielle qui se forme à basse température par précipitation de précurseurs minéraux et organiques sécrétés par l'utérus. La minéralisation de la coquille se caractérise par une précipitation spontanée de carbonate de calcium sur une membrane dans un milieu acellulaire.

Figure 7. Degré de saturation des ions calcium et bicarbonates par rapport à la solubilité de la calcite (Gomez-Morales et Garcia-Ruiz, communication personnelle).

En pointillé, dépôt de la coquille en g. Les courbes de ronds noirs ou ouverts correspondent à deux échantillonnages prélevés sur 2 lots de poules et représentent au cours de la formation de la coquille le degré de saturation en ions calcium et bicarbonates dans le fluide utérin (rapport entre produit ionique et solubilité de la calcite).

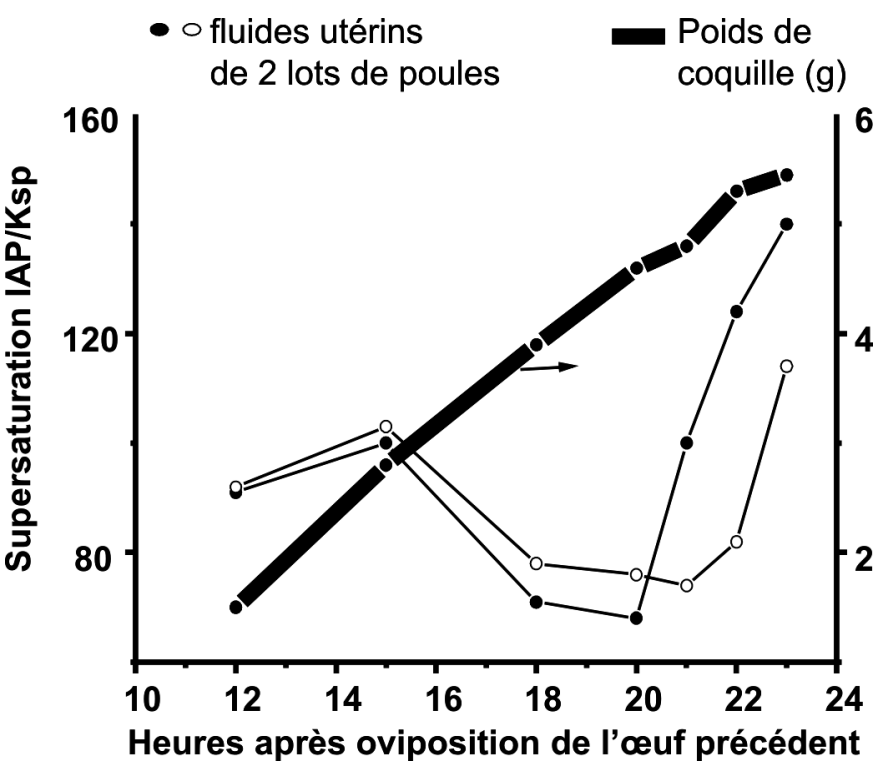


Figure 8. Photographies en microcopie à balayage de la face interne de coquilles au contact des membranes coquillières de différentes espèces d'oiseaux domestiques (Panhéleux et al 1999a).
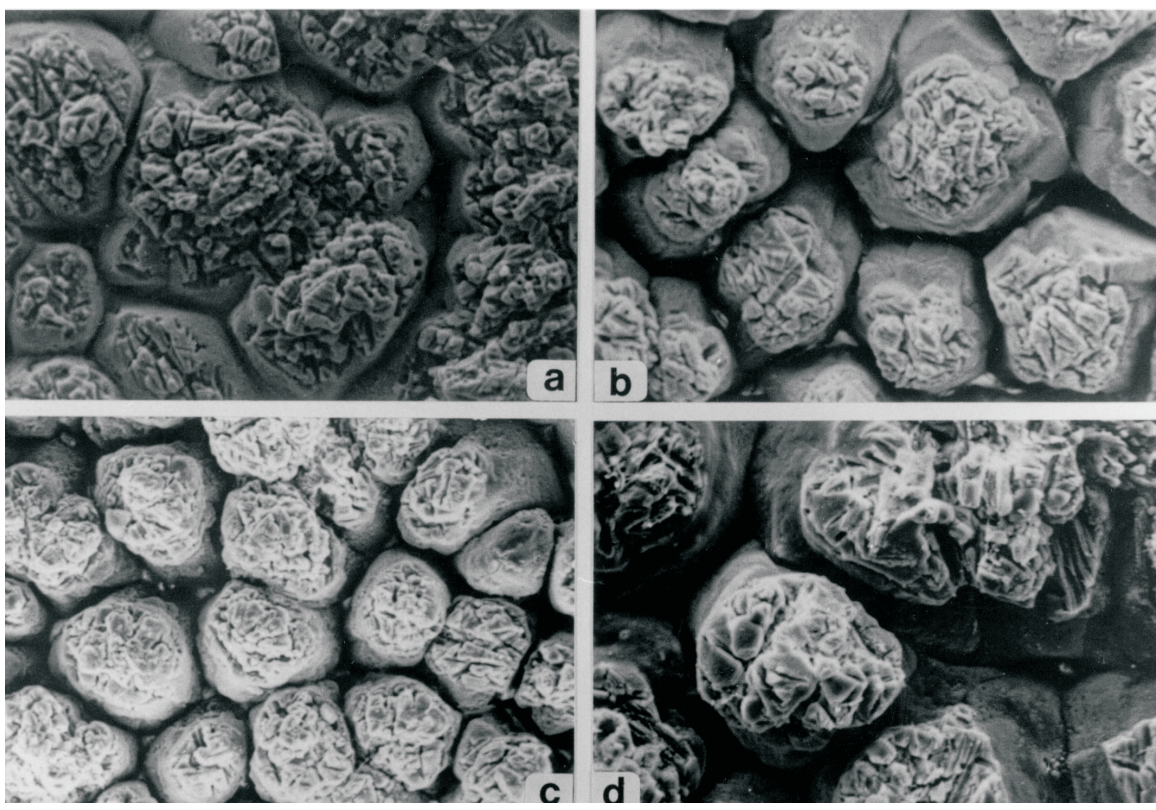

Les tissus minéralisés des organismes vivants diffèrent les uns des autres par leur forme, leur composition minérale, leur ultrastructure, leur texture cristallographique et leur fabrication. Le tissu osseux se forme grâce à une participation active des cellules osseuses et la mise en place d'une matrice organique (collagène), progressivement minéralisée par du phosphate de calcium. Pour bâtir une coquille, la poule sécrète des ions calcium et bicarbonates et des constituants organiques qui s'autoassemblent sur une membrane. Cela est possible si le milieu est délimité et saturé en ions minéraux ; la saturation étant atteinte, les ions précipitent et les cristaux apparaissent. La coquille des œufs d'oiseaux se forme dans le fluide contenu entre l'œuf en formation et la paroi tubulaire de l'oviducte distal. L'œuf dilaté est en rotation autour de son grand axe et baigne dans le fluide utérin qui contient $70 \mathrm{mM}$ d'ions bicarbonate (Sauveur et Mongin 1971) et 6 à $10 \mathrm{mM}$ de calcium sous forme ionique (Nys et al 1991). La concentration en ions précurseurs du carbonate de calcium est, pendant toutes les phases de minéralisation de la coquille, de 80 à plus de 120 fois supérieures à la quantité maximale dissoute de calcite (Ksp ; figure 7). Le carbonate de calcium précipite par conséquent spontanément. Le précipité se présente sous forme de calcite, polymorphe du carbonate de calcium thermodynamiquement le plus stable à température et à pression atmosphérique ambiantes. Ce sont les constituants organiques présents dans le fluide utérin qui favorisent ce type de polymorphe par rapport à l'aragonite ou à la Ruiz 2000). des premiers cristaux en des sites prédéterminés, et la sécrétion, pendant la phase de croissance cristalline, de molécules organiques qui interagissent avec le cristal en formation. La répartition des sites de nucléation en surface des membranes est sous contrôle génétique et varie selon les espèces (figure 8). Elle détermine la taille des cônes, le diamètre des cylindres de la couche compacte de la coquille et, au final, la solidité de la coquille. L'équipe de Grenade (Garcia-Ruiz et Rodriguez-Navarro 1994) a modélisé l'influence de la répartition des sites de nucléation, de l'arrondi de l'œuf et de la morphologie des cristaux sur la taille de ces derniers et leur orientation qui déterminent les propriétés mécaniques de la coquille. Cette modélisation ne permet pas, cependant, de conclure sur une répartition idéale des sites de nucléation.

Au cours de la 1ère phase de minéralisation, la croissance des cristaux de calcite est radiale. Elle est inhibée vers l'intérieur de l'œuf par la présence des fibres membranaires (cf. figure 1). Les sites de nucléation constituent le point de départ des cônes qui progressivement se rejoignent pour former la base de la couche palissadique. La construction de la coquille d'œuf résulte d'une compétition entre sites de cristallisation voisins, car la rencontre de deux cristaux adjacents inhibe leur croissance dans cette direction (figure 9, Rodriguez-Navarro et Garcia-Ruiz 2000).

La croissance cristalline ne se poursuit que dans l'espace libre, donc uniquement pour les cristaux dont l'axe de croissance est perpendiculaire à la

Figure 9. Modélisation de la mise en place de la texture de la coquille par compétition d'espace entre sites de nucléations adjacents (Rodriguez-Navarro et Garcia-

Seuls les cristaux dont la direction de croissance est proche de la perpendiculaire à la surface ne sont pas bloqués par des cristaux adjacents.

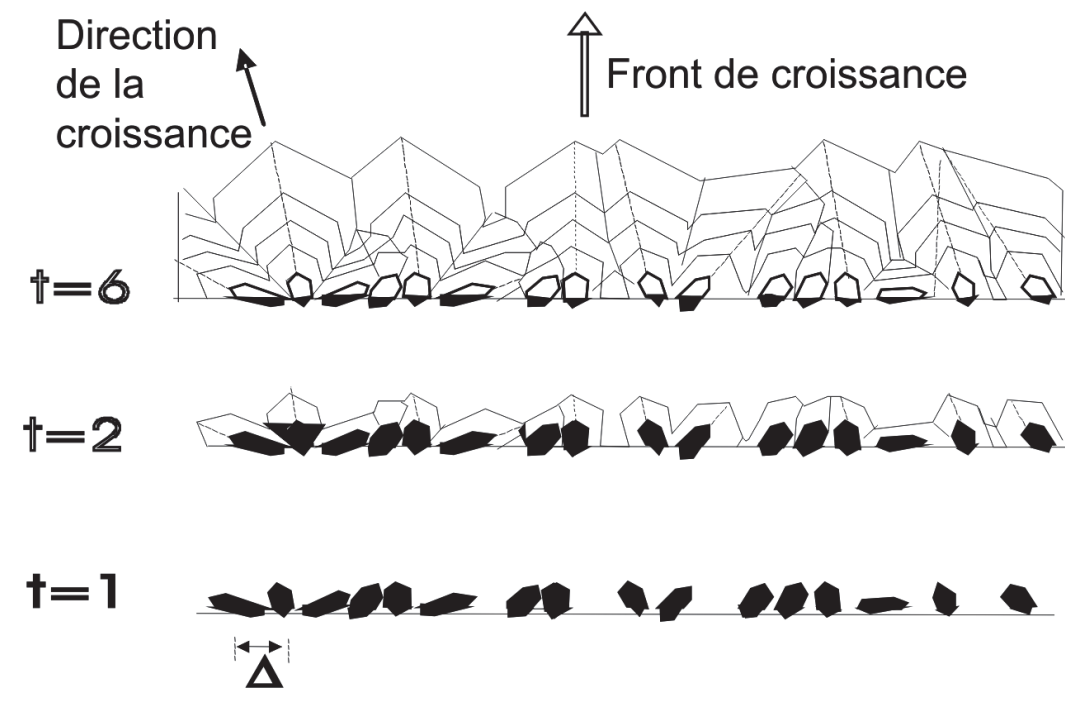


Encadré 2. Sécrétion de calcium par l'utérus

Le dépôt de carbonate de calcium permettant la formation de la coquille dans l'utérus est un processus discontinu de chronologie précise. La capacité de l'utérus à transporter le calcium reflète cette chronologie. La dilatation provoquée par la présence de l'œuf favorise la sécrétion de calcium, uniquement lorsqu'elle coïncide avec une période de calcification de la coquille. L'introduction d'un jaune artificiel provoque toujours un dépôt d'albumen et de membranes coquillières, mais n'induit une calcification de l'œuf que si l'entrée du leurre coïncide avec l'ovulation d'un jaune. La sécrétion du calcium dans la lumière de l'utérus se fait contre le gradient de concentration; elle est fortement diminuée en présence d'inhibiteurs de la pompe à sodium ou de l'anhydrase carbonique. La sécrétion du calcium est associée à un grand nombre de co-transports, canaux et pompes à ions $\mathrm{Na}^{+}, \mathrm{K}^{+}, \mathrm{Cl}$ et $\mathrm{H}^{+}$(Eastin et Spaziani 1978a et b). L'identification des gènes codant les protéines transporteuses de $\mathrm{Ca}^{++}$et autres minéraux de l'utérus confirme et enrichit les hypothèses sur les mécanismes de transport décrites dans la figure 10 (Jonchère et al 2010b).

Figure 10. Schéma des systèmes de transfert utérin lors de la calcification pompe ionique, canal ionique, $\odot$ échangeur ionique, $\hookrightarrow$ hydrolyse ATP.

Plasma sanguin Cellules glandulaires Fluide utérin

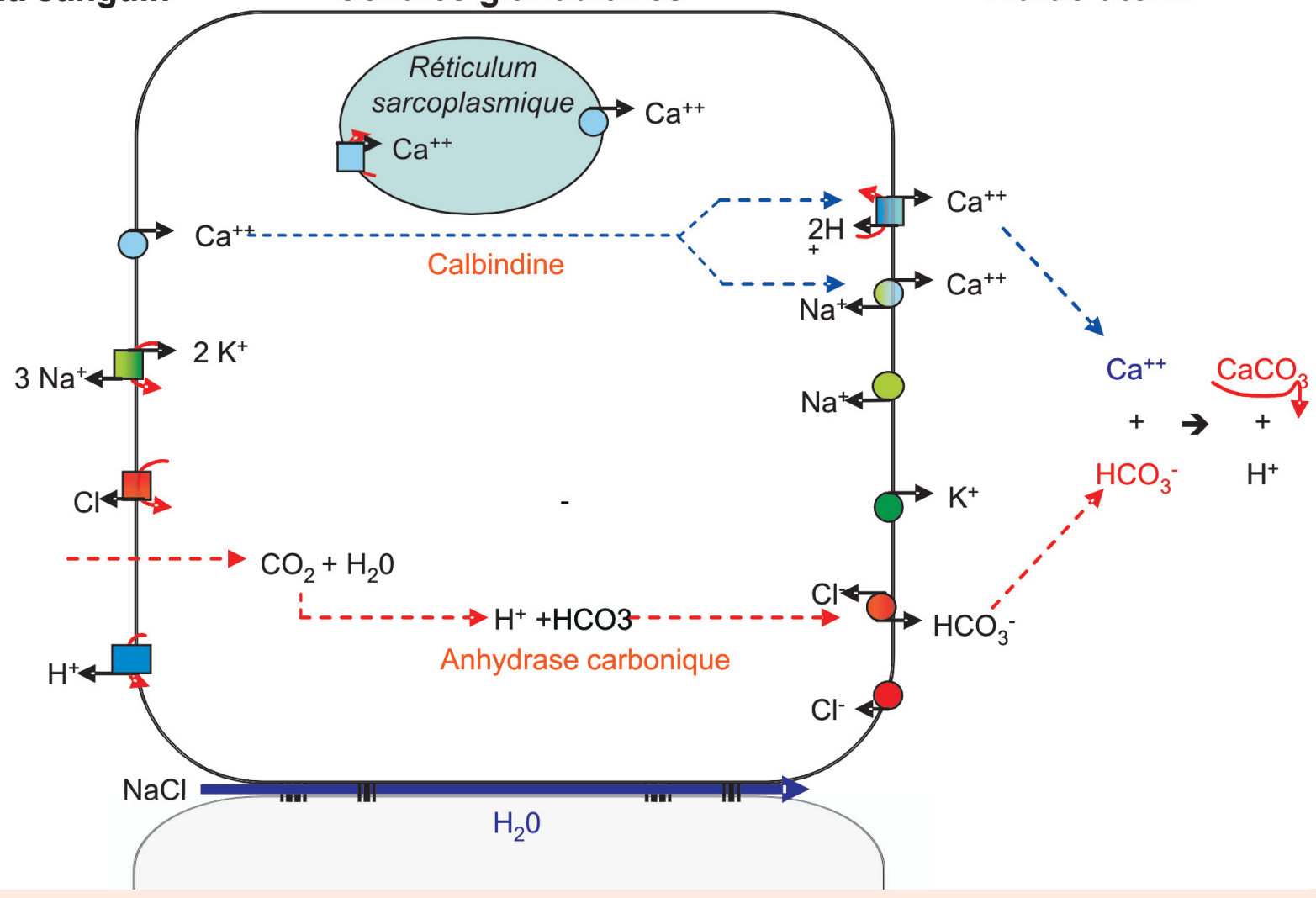

Le calcium pénètre selon le gradient de concentration dans les cellules utérines par un canal calcique (TRPV6). Son transport du pôle basal vers le pôle apical est assuré par la calbindine D28K dans le cytosol. II transite ensuite via le réticulum endoplasmique. Plusieurs pompes et canaux sont responsables de l'intrusion et extrusion du calcium dans cet organite (SERCA et ITPR). L'extrusion du calcium vers le fluide utérin est assurée par une pompe calcique (PMCA) et par un échangeur sodium/calcium (NCX).

La réabsorption du sodium est assurée par un canal sodique $(\mathrm{ENaC})$, un échangeur $\mathrm{Na}^{+} / \mathrm{Ca}^{++}(\mathrm{NCX})$ et l'échangeur $\mathrm{Na}^{+} / \mathrm{K}^{+}$(pompes à sodium ATP1A1 et ATP1B1). Le $\mathrm{CO}_{2}$ diffuse librement à travers la membrane plasmique pour produire les ions bicarbonates grâce à l'anhydrase carbonique II. Son exportation de la cellule vers la lumière utérine est assurée par un échangeur $\mathrm{HCO}_{3}{ }^{+} / \mathrm{Cl}^{-}(\mathrm{SLCA})$. La précipitation du carbonate de calcium dans le fluide utérin engendre la production de 2 protons pour chaque ion bicarbonate. Ces protons sont réabsorbés du fluide utérin vers la cellule par un échange $\mathrm{Ca}^{++} / \mathrm{H}^{+}$puis vers le plasma par une pompe à protons $\left(\mathrm{VH}^{+}\right.$-ATPase) et un échangeur $\mathrm{Cl}^{-} / \mathrm{H}^{+}$(canal CLCN5). La réabsorption du chlore vers le plasma est assurée par les pompes CLCN2 et CFTR. Enfin, la sécrétion du potassium dépend de l'échangeur $\mathrm{Na}^{+} / \mathrm{K}^{+}$-ATPase.

La calbindine cytosolique protège la cellule d'un excès de calcium. Le transfert de calcium dans l'utérus est donc étroitement corrélé avec sa concentration, comme cela est observé dans l'intestin. La concentration de la calbindine utérine augmente fortement lors de la mise en place de la production d'œufs, au cours de la 1 ère calcification et se maintient à un niveau élevé tant que la production d'œufs se poursuit. Contrairement à ce qui est observé dans l'intestin, la vitamine D n'est pas indispensable à la synthèse de calbindine dans l'utérus et ne peut stimuler, au niveau de l'utérus, la quantité de coquille déposée. Son gène est surexprimé lors de chaque calcification de la coquille et cette expression chute rapidement quand la calcification de l'œuf est supprimée. La régulation de la calbindine utérine est associée, pour sa composante principale, au flux de calcium et/ou à un facteur intracellulaire dont la teneur est modifiée par ce flux. 
surface de la coquille en formation. Cette hypothèse explique l'observation d'une orientation privilégiée dans la partie supérieure de la coquille. Elle suppose l'existence d'une croissance anisotrope des cristaux de calcite, c'està-dire d'une croissance inégale des faces cristallines entre les différentes directions. Cette hétérogénéité de croissance selon différentes directions résulte en fait de l'action de constituants de la matrice organique, qui se lient aux faces parallèles à l'axe $\mathrm{C}$ de la calcite par des liaisons hydrostatiques ou hydrophobes et inhibent par conséquent la croissance de celle-ci latéralement, favorisant l'élongation du cristal (Hernandez-Hernandez et al 2008a, $b$ et c). L'observation ré-cente selon laquelle un des constituants organiques de la coquille, l'ostéopontine, est localisé préférentiellement sur un ensemble de ces faces de la calcite (Hincke et al 2008), confirme le rôle de la matrice organique dans le contrôle de la texture minérale. Au stade d'arrêt de la calcification, $1 \mathrm{~h} 30$ avant l'oviposition, le fluide utérin reste cependant très riche en ions calcium et bicarbonate ; l'arrêt de la calcification est donc dû à une inhibition de la minéralisation, probablement par un constituant phosphoré puisque le phosphore est présent uniquement dans les couches superficielles de la coquille (Quintana et Sandoz 1978 ) et constitue par ailleurs un «poison» connu de la cristallisation des carbonates de calcium.

\section{3 / Origine des constituants minéraux de la coquille (encadré 2)}

Le calcium n'est pas stocké dans l'utérus avant la calcification de la coquille. Il provient du calcium ionique sanguin et est transféré dans le fluide utérin contre son grandient de concentration (encadré 2). Son renouvellement est extrêmement rapide au cours de la calcification puisque le pool total de calcium plasmatique est renouvelé toutes les $12 \mathrm{~min}$ (cf. revues de Sauveur 1988, Nys 2010). La source de calcium est toujours alimentaire, mais du fait d'une désynchronisation entre l'apport alimentaire diurne, et la formation nocturne de la coquille, l'os contribue pour 30 à $40 \%$ au calcium déposé dans la coquille. Cette mobilisation est facilitée par la présence de l'os médullaire localisé autour de la moelle dans les os longs des oiseaux. Au cours de la calcification, la surface de résorption de l'os médullaire est multipliée par 9, mais une activité ostéoblastique de formation de l'os se maintient et reconstitue cet os labile. Les ions carbonates constituent $60 \%$ de la coquille et proviennent du gaz carbonique sanguin. L'hydratation du $\mathrm{CO}_{2}$ est catalysée par l'anhydrase carbonique présente dans les cellules des glandes tubulaires. Elle s'accompagne d'une réabsorption d'ions hydrogène à l'origine d'une acidose métabolique, compensée par une hyperventilation respiratoire et une excrétion rénale (Mongin 1978).

\section{4 / Evidences d'un contrôle de la construction de la coquille par les protéines de sa matrice organique}

Un ensemble d'éléments démontre le rôle fonctionnel des constituants organiques dans la fabrication de la coquille. C'est tout d'abord 1) un profil protéique particulier du fluide utérin à chaque étape de la minéralisation, 2) la démonstration in vitro de modifications de la cinétique de cristallisation et de la morphologie de la calcite en présence de ces molécules, 3) l'association in vivo entre les propriétés ultrastructurales ou mécaniques de la coquille et la concentration des protéines de sa matrice ou des polymorphes simples nucléotidiques (SNP) de gènes codant les protéines impliquées dans la minéralisation, 4) les analogies et particularités entre coquilles de divers oiseaux.

\section{1 / Variation de la composition du fluide utérin}

C'est dans ce milieu acellulaire que se forme la coquille à partir des sécrétions minérales et organiques issues de l'isthme et de l'utérus. Les conditions physico-chimiques de ce milieu restent relativement stable en termes d'hypersaturation vis-à-vis du calcium et des bicarbonates pendant les trois phases d'initiation, de croissance et d'arrêt de la calcification (Nys et al 1991) mais chaque étape se caractérise par un profil différent de protéines, qui est révélé par électrophorèse (Gautron et al 1997). Nous avons également démontré, grâce à l'utilisation d'anticorps spécifiques ou par séquençage des bandes électrophorétiques, que de nombreuses protéines du fluide utérin, ovalbumine, ovotransferrine, mais aussi ovocléidines et ovocalyxines étaient à la fois présentes dans le fluide utérin et dans les extraits de coquille, confirmant donc la présence des précurseurs de la matrice organique de la coquille dans ce milieu (Gautron et al 1997). Lorsque du fluide utérin est collecté, le carbonate de calcium précipite en quelques minutes en incluant une part des protéines de la matrice. En effet, l'observation du profil électrophorétique du fluide utérin avant et après précipitation spontanée de calcite (Gautron et al 1997, Hernandez-Hernandez et al 2008a) révèle la disparition de protéines particulières qui s'intègrent dans la phase minérale, notamment l'ovocléidine-116 et l'ovocalyxine-32.

\section{2 / Modification de la minérali- sation du carbonate de calcium in vitro en présence de consti- tuants organiques}

Le premier test utilisé pour analyser l'implication des protéines de la matrice organique dans la minéralisation mesure in vitro la vitesse de précipitation du carbonate de calcium en enregistrant les variations concomitantes du $\mathrm{pH}$ du milieu. Cette approche a révélé que la fraction organique soluble de la coquille retarde la précipitation du carbonate de calcium d'une manière dose-dépendante (Gautron et al 1996). Un effet similaire a été observé lors de l'introduction de fractions riches en protéoglycanes (Arias et al 1993) et de macromolécules contenues dans le fluide utérin (Gautron et al 1997). Une microméthode réalisée avec des concentrations ioniques plus faibles a amélioré considérablement la reproductibilité en termes de cinétique de précipitation et d'homogénéité de la morphologie des cristaux produits (DominguezVera et al 2000, Hernandez-Hernandez et al 2008a, b et c). Ce test a démontré que le fluide utérin contrôle le type polymorphique du carbonate de calcium puisqu'en présence de faibles concentrations de fluide utérin et quel que soit le stade de prélèvement, seule la calcite se forme in vitro. Au contraire, dans le lot témoin où les protéines sont absentes, les trois polymorphes du carbonate de calcium, calcite, aragonite et vatérite, sont présents à 50 , 25 et $25 \%$ respectivement (HernandezHernandez et al 2008a et c, figure 11).

L'introduction de fluide utérin diminue de près de 1000 fois le temps de latence pour obtenir les premiers cristaux, augmente considérablement leur nombre ( $>10000$ ou lieu de 40) et réduit de 5 à 20 fois leur taille. La morphologie des cristaux de calcite est fortement modifiée en présence de fluide utérin. Des modifications tout aussi importantes de la cinétique de formation du cristal, de sa taille et de sa morphologie, sont observées quand des extraits solubles de la matrice organique de la coquille sont introduits dans un test de croissance des cristaux de carbonate de calcium in vitro (Gautron et al 1996, Dominguez-Vera et al 2000, Hernandez-Hernandez et al 2008b, figure 12).

De nombreuses tentatives ont été réalisées pour identifier les constituants responsables de cette interaction avec le cristal en formation. La morphologie des cristaux de calcite est fortement 
Figure 11. Modification du polymorphe, du carbonate de calcium en présence de fluide utérin (Hernandez et al $2008 \mathrm{a}$ et c).

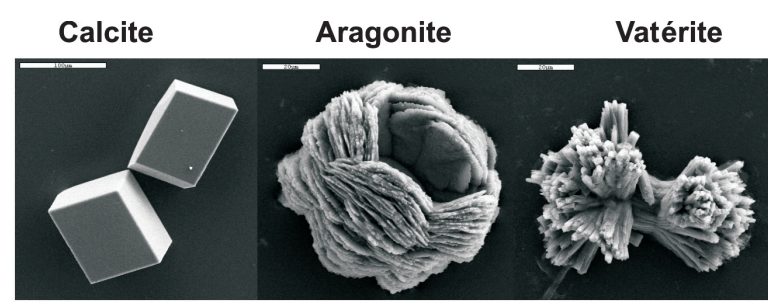

\section{Contrôle (\%) $\quad 55 \quad 22,5 \quad 22,5$}

Fluide Utérin (\%) $100 \quad 00$

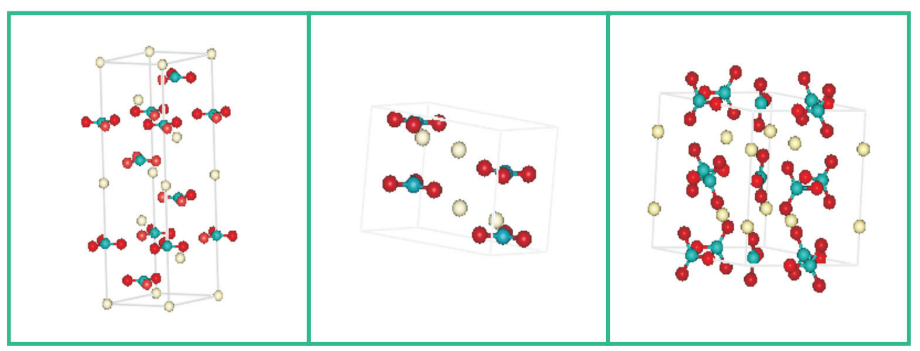

Figure 12. Modification de la morphologie des cristaux de calcite en présence de fluide utérin ou d'extrait de coquille. a et $\boldsymbol{b}$ : calcite en présence de 128 et $512 \mu \mathrm{g} / \mathrm{ml}$ d'ovotransferrine. c : vatérite en présence de $512 \mu \mathrm{g} / \mathrm{ml}$ d'ovotransferrine. d et e : calcite en présence de 128 and $512 \mu \mathrm{g} / \mathrm{ml}$ d'ovalbumine ; $\boldsymbol{f}$ : vatérite en présence de $512 \mu \mathrm{g} / \mathrm{ml}$ d'ovalbumine. $\boldsymbol{g}$ : calcite en présence de fluide utérin en phase initiale; $\boldsymbol{h}$ : phase de croissance et $\boldsymbol{i}:$ terminale. Coquille de poule : $\boldsymbol{j}:$ couche mamillaire de la coquille. $\boldsymbol{k}$ : couche palissadique. I : couche apicale de cristaux verticaux (Hernandez-Hernandez et al 2008a et b).
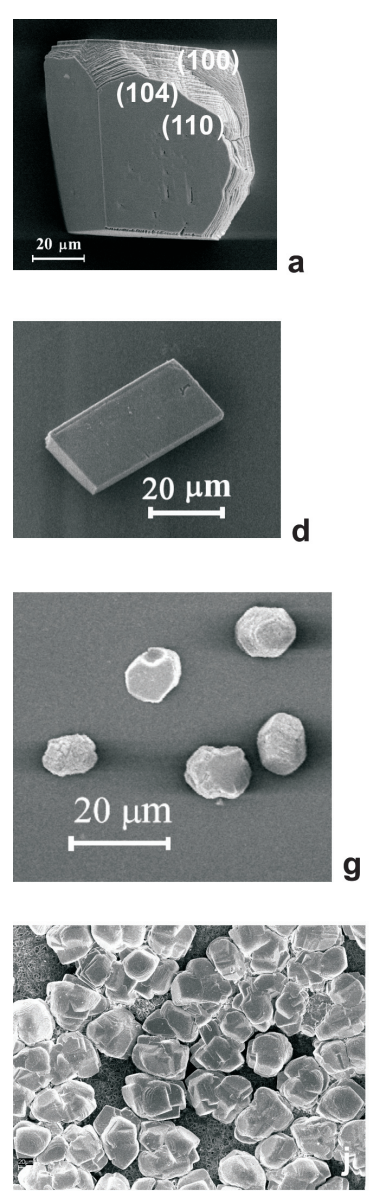
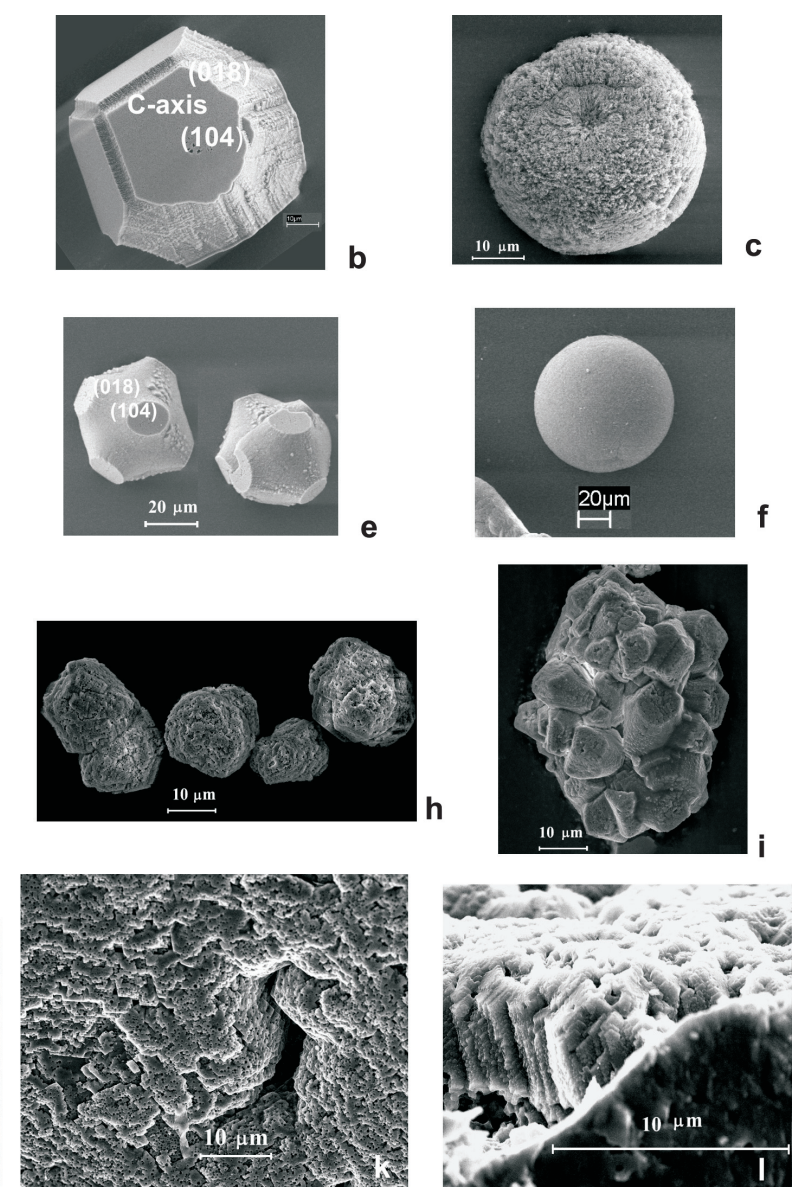
modifiée en présence de lysozyme, d'ovotransferrine, d'ovocléidine-17 de poule (Hincke et al 2000, Gautron et al 2001a, Reyes-Grajeda et al 2004) ou d'ansocalcine d'oie (Lakshminarayanan et al 2002), et plus particulièrement du fait de ses acides aminés chargés présents dans sa partie centrale (Ajikumar et al 2005). Par exemple, l'ovotransferrine $(500 \mu \mathrm{g} / \mathrm{ml})$ induit une modification caractéristique: les faces $\{104\}$ restent planes mais leurs arêtes, qui convergent sur l'axe $\mathrm{C}$, présentent un aspect irrégulier avec apparition de faces $\{018\}$. Le cristal s'allonge et forme une structure en chevrons qui rappelle des observations de la couche palissadique de coquille (figure $12 \mathrm{a}, \mathrm{b}$ et c, Gautron et al 2001a, HernandezHernandez et al 2008c ). Chez la poule, un candidat probable est un protéoglycane à dermatane sulfate du fait de ses caractéristiques polyanioniques (Arias et al 2002). Son cœur protéique correspond à l'ovocléidine 116 (Hincke et al 1999). Une étude montre d'ailleurs que les interactions sur la croissance de la calcite et les modifications de sa morphologie par 4 protéines de même conformation sont d'autant plus accentuées que leur charge négative est élevée (Hernandez-Hernandez et al 2008 b) ; des protéines phosphorylées telles que l'ostéopontine, l'ovocléidine 17 , l'ovocleidine 116 et l'ovocalyxine 32 sont des candidates très probables. L'ostéopontine semble interférer avec la face $\{104\}$ de la calcite, qui correspond à un plan de clivage, et pourrait ainsi modifier les propriétés mécaniques de la coquille (Chien et al 2008). Récemment, des fractions chromatographiques d'extraits de coquille affectant à faible concentration la croissance de la calcite ont été purifiées mais leur caractérisation par spectrométrie de masse ne révèle pas une protéine dominante (Hernandez-Hernandez et al 2008a). L'ensemble de ces observations in vitro confortent l'hypothèse d'un contrôle par des protéines de la matrice du processus de minéralisation de la coquille d'œuf.

\section{3 / Relation entre matrice organique de la coquille et ses propriétés mécaniques}

Les résultats expérimentaux in vitro sont confirmés par des observations in vivo. De nombreux facteurs de variations nutritionnelles, génétiques ou physiologiques (âge, mue) affectent la solidité de la coquille. Chez les poules en fin de production, la diminution de la proportion de coquille n'explique qu'une part de la réduction de résistance à la rupture. Elle coïncide avec une modification des proportions relatives de protéines de la matrice de la coquille (Panhéleux et al 2000) et de la texture cristallographique de celleci (Rodriguez-Navarro et Romanek 2002). La mue rétablit la solidité de la coquille et inverse les variations précédemment observées pour la matrice de la coquille et sa texture (Ahmed et al 2005). Par ailleurs, des déficits d'expression de l'ostéopontine dans des sites particuliers de l'épithélium de l'utérus semblent être associés à des défauts de structure de la coquille (Arazi et al 2009). Enfin, la recherche d'une association entre le polymorphisme de gènes codant des protéines de la coquille et sa solidité a révélé l'existence d'allèles de l'ostéopontine associés à la dureté de la coquille, de l'ovocléidine 116 liés à l'élasticité et à l'épaisseur de la coquille et de l'ovocalyxine 32 corrélés à l'épaisseur de la couche mamillaire (Dunn et al 2009).

\section{4 / Etude comparative de coquilles de diverses espèces}

La structure des coquilles de diverses espèces est similaire. Quand de très nombreuses espèces sont comparées, une forte relation linéaire est observable entre poids de l'œuf et poids de la coquille d'une part, et entre résistance à la rupture et poids de la coquille d'autre part (Ar et al 1979). Cependant, chaque groupe d'oiseaux présente des particularités dans la forme des pores, leur ultrastructure et leurs propriétés cristallographiques (von Nathusius, traduit par Tyler 1964, Board 1982). Entre coquilles d'oiseaux domestiques, nous avons observé quelques particularités ultrastructurales au niveau de la couche des cônes sans pouvoir les associer à une modification de la composition de leur matrice organique (Panhéleux et al 1999a). Ce travail a confirmé la présence de protéines communes à plusieurs espèces (ovocléidine, ovalbumine, ostéopontine, ovotransferrine) indiquant une certaine universalité. La pintade est un cas très particulier. Elle présente une quantité de coquille dont la résistance à la rupture est très supérieure à celle des autres espèces quand les corrections pondérales sont réalisées. Ces propriétés résultent d'une texture très originale (Panhéleux et al 1999b) dans laquelle les cristaux de calcite sont entrelacés dans la partie extérieure de la couche calcifiée alors que chaque colonne reste individualisée chez la poule (figure 3). Cette modification de texture confirme l'existence d'une régulation active en cours de calcification, mais l'origine de ce contrôle reste encore indéterminée.

\section{Conclusion}

Des progrès considérables ont été réalisés depuis 15 ans dans l'identification des constituants de la matrice organique de la coquille et il n'existe plus aucun doute sur leur intervention dans le contrôle de la fabrication de ce biomatériau et l'établissement de ses propriétés mécaniques. De nombreux constituants de la matrice ont été identifiés, mais le rôle spécifique de chacun n'est pas défini, ni leur mode d'interaction avec la phase minérale qui contrôlerait l'ultrastructure, la texture, la porosité et la solidité de la coquille. Une compréhension de la régulation de la synthèse de ces protéines permettrait d'analyser le contrôle génétique de ce processus et de renforcer cette protection physique pour optimiser le développement embryonnaire et la qualité sanitaire de l'œuf.

\section{Références}

Ahmed A.M., Rodriguez-Navarro A.B., Vidal M.L., Gautron J., Garcia-Ruiz J.M., Nys Y., 2005. Changes in eggshell mechanical properties, crystallographic texture and in matrix proteins induced by moult in hens. Brit. Poult. Sci., 46, 268-279.

Ajikumar P.K., Vivekanandan S., Lakshminarayanan R., Jois S.D.S., Kini R.M., Valiyaveettil S., 2005. Mimicking the function of eggshell matrix proteins: The role of multiplets of charged amino acid residues and selfassembly of peptides in biomineralization. Angew. Chem. Int. Ed. Eng., 44, 5476-5479.
Ar A., Rahn H., Paganelli C.V., 1979. The avian egg: Mass and strength. Condor, 81, 331337.

Arazi H., Yoselewitz I., Malka Y., Kelner Y. Genin O., Pines M., 2009. Osteopontin and calbindin gene expression in the eggshell gland as related to eggshell abnormalities. Poult. Sci. $88,647-653$.

Arias J.L., Fink D.J., Xiao S.Q., Heuer A.H. Caplan A.I., 1993. Biomineralization and eggshells: Cell-mediated acellular compartments of mineralized extracellular matrix. Int Rev. Cytol., 145, 217-250.
Arias J.I., Jure C., Wiff J.P., Fernandez M.S., Fuenzalida V., Arias J.L., 2002. Effect of sulfate content of biomacromolecules on the crystallization of calcium carbonate. Mat. Res. Soc. Symp. Proc., 711, 243-248.

Bar A., 2008. Calcium homeostasis and vitamin $\mathrm{d}$ metabolism and expression in strongly calcifying laying birds. Comp. Biochem. Physiol. A Mol. Integr. Physiol., 151, 477-490.

Board R.G., 1982. Properties of avian eggshells and their adaptative value. Biol. Rev., 57, 1-28. 
Carrino D.A., Rodriguez J.P., Caplan A.I., 1997. Dermatan sulfate proteoglycans from the mineralized matrix of the avian eggshell. Connect. Tissue Res., 36, 175-193.

Chien Y.C., Hincke M.T., Vali H., Mckee M.D., 2008. Ultrastructural matrix-mineral relationships in avian eggshell, and effects of osteopontin on calcite growth in vitro. J. Struct. Biol., 163, 84-99.

Chowdhury S.D., 1990. Shell membrane system in relation to lathyrogen toxicity and copper deficiency. World's Poult. Sci. J., 46, 153-169.

Dennis J.E., Xiao S.Q., Agarwal M., Fink D.J., Heuer A.H., Caplan A.I., 1996. Microstructure of matrix and mineral components of eggshells from white leghorn chickens (Gallus Gallus). J. Morphol., 228, 287-306.

Dominguez-Vera J.M., Gautron J., GarciaRuiz J.M., Nys Y., 2000. The effect of avian uterine fluid on the growth behavior of calcite crystals. Poult. Sci., 79, 901-917.

Dunn I.C., Wilson P.W., Lu Z., Bain M.M., Crossan C.L., Talbot R.T., Waddington D. 2009. New hypotheses on the function of the avian shell gland derived from microarray analysis comparing tissue from juvenile and sexually mature hens. Gen. Comp. Endocrinol., $163,225-232$.

Eastin W.C., Spaziani E., 1978a. Control of calcium secretion in avian shell gland (uterus). Biol. Reprod., 19, 493-504.

Eastin W.C., Spaziani E., 1978b. On the mechanism of calcium secretion in the avian shell gland (uterus). Biol. Reprod., 19, 505518 .

Fernandez M.S., Araya M., Arias J.L., 1997. Eggshells are shaped by a precise spatiotemporal arrangement of sequentially deposited macromolecules. Matrix Biol., 16, 13-20.

García-Ruiz J.M., Rodríguez-Navarro A. 1994. Competitive crystal growth: The avian eggshell model, In: Biomineralization 93 Allemand D., Cuif, J.P. (Eds). Musée Océanographique de Monaco, 85-94.

Gautron J., Nys Y., 2007. Function of eggshell matrix proteins. In: Bioactive egg compounds. Heidelberg S.B. (Ed). Springer Berlin Heidelberg, UK, 103-108.

Gautron J., Nys Y., 2010. Coquille et membrane coquillière. Chap 1. Composition de l'œuf. In : Science et technologie de l'œuf et des ovoproduits, Nau F., Guérin-Dubiard C., Baron F., Thapon J.L. (Eds). Editions Tec et Doc Lavoisier, Paris, France, 2, 1-174.

Gautron J., Bain M., Solomon S., Nys Y., 1996. Soluble matrix of hen's eggshell extracts changes in vitro the rate of calcium carbonate precipitation and crystal morphology. Brit. Poult. Sci., 37, 853-66.

Gautron J., Hincke M.T., Nys Y., 1997. Precursor matrix proteins in the uterine fluid change with stages of eggshell formation in hens. Connect.Tissue Res., 36, 195-210.

Gautron J., Hincke M.T., Panhéleux M., Garcia-Ruiz J.M., Boldicke T., Nys Y., 2001a. Ovotransferrin is a matrix protein of the hen eggshell membranes and basal calcified layer. Connect. Tissue Res., 42, 255-267.

Gautron J., Hincke M.T., Mann K., Panhéleux M., Bain M., Mckee M.D., Solomon S.E., Nys Y., 2001b. Ovocalyxin-32, a novel chicken eggshell matrix protein: Isolation, amino acid sequencing, cloning and immunocytochemical localization. J. Biol. Chem., 276, 39243-39252.

Gautron J., Murayama E., Vignal A., Morisson M., Mckee M.D., Rehault S., Labas V., Belghazi M., Vidal M.L., Nys Y., Hincke M.T., 2007. Cloning of ovocalyxin-36, a novel chicken eggshell protein related to lipopolysaccharide-binding proteins, bactericidal permeability-increasing proteins, and plunc family proteins. J. Biol. Chem., 282, 5273-5286.

Guinotte F., Nys Y., 1993. Factors affecting the intestinal calcium availability in laying hens: consequences on shell quality. In: Proc. V Europ. Symp. on the Quality of egg and eggs products, Tours, Nys Y. (Ed), 149-162.

Hernandez-Hernandez A., Gomez-Morales J., Rodriguez-Navarro A.B., Gautron J., Nys Y., Garcia-Ruiz J.M. 2008a. Identification of some active proteins in the process of hen eggshell formation. Cryst. Growth Des., 8, 4330-4339.

Hernandez-Hernandez, A., RodriguezNavarro, A.B., Gomez-Morales, J., JimenezLopez, C., Nys, Y., Garcia-Ruiz, J.M., 2008b Influence of model globular proteins with different isoelectric points on the precipitation of calcium carbonate. Cryst. Growth Des., 8, 1495-1502.

Hernandez-Hernandez A., Vidal M.L., Gomez-Morales J., Rodriguez-Navarro A.B. Labas V., Gautron J., Nys Y., Garcia-Ruiz J.M. 2008c. Influence of eggshell matrix proteins on the precipitation of calcium carbonate (CaCO3). J. Crystal Growth, 310, 17541759 .

Hincke M.T., 1995. Ovalbumin is a component of the chicken eggshell matrix. Connect Tissue Res., 31, 227-233.

Hincke M.T., Tsang C.P., Courtney M., Hill V., Narbaitz R., 1995. Purification and immunochemistry of a soluble matrix protein of the chicken eggshell (ovocleidin 17). Calcif. Tissue Int., 56, 578-583.

Hincke M.T., Gautron J., Tsang C.P., Mckee M.D., Nys Y., 1999. Molecular cloning and ultrastructural localization of the core protein of an eggshell matrix proteoglycan, ovocleidin116. J. Biol. Chem., 274, 32915-32923.

Hincke M.T., Gautron J., Panheleux M. Garcia-Ruiz J., Mckee M.D., Nys Y., 2000 Identification and localization of lysozyme as a component of eggshell membranes and eggshell matrix. Matrix Biol., 19, 443-453.

Hincke M.T., Wellman-Labadie O., McKee M. D., Gautron J., Nys Y., Mann K., 2008. Biosynthesis and structural assembly of eggshell components. In: Bioscience and biotechnology, Mine Y. (Ed). Egg John Willey \& Sons, Inc., Hoboken, New-Jersey, 97-128.

Jonchère V., Réhault-Godbert S., Hennequet-Antier C., Cabau C., Sibut V., Cogburn L.A., Nys Y., Gautron J., 2010a. Gene expression profiling to identify eggshell proteins involved in physical defense of the chicken egg. BMC Genomics, 11, 57, 19p.

Jonchère V., J. Gautron, Narcy A., Brionne A., J. Nys Y., 2010b. Gene identification coding uterine proteins supplying the minerals for eggshell formation. Proc.XIII Eur. Poult Conf., Tours 23-27th August, Editors Duclos M., Nys Y., WPSA-France.

Lakshminarayanan R., Kini R.M. Valiyaveettil S., 2002. Investigation of the role of ansocalcin in the biomineralization in goose eggshell matrix. Proc. Natl. Acad. Sci. U.S.A., 99, 5155-5159.

Lavelin I., Yarden N., Ben-Bassat S., Bar A., Pines M., 1998. Regulation of osteopontin gene expression during egg shell formation in the laying hen by mechanical strain. Matrix Biol., 17, 615-623.

Mann K., 2004. Identification of the major proteins of the organic matrix of emu (dromaius novaehollandiae) and rhea (rhea americana) eggshell calcified layer. Brit. Poult. Sci., $45,483-490$

Mann K., Siedler F., 2004. Ostrich (Struthio Camelus) eggshell matrix contains two different c-type lectin-like proteins. Isolation, amino acid sequence, and posttranslational modifications. Biochim. Biophys. Acta, Proteins and Proteomics, 1696, 41-50.

Mann K., Siedler F., 2006. Amino acid sequences and phosphorylation sites of emu and rhea eggshell c-type lectin-like proteins. Comp. Biochem. Physiol. B Biochem. Mol. Biol., 143, 160-170.

Mann K., Gautron J., Nys Y., Mckee M.D., Bajari T., Schneider W.J., Hincke M.T. 2003. Disulfide-linked heterodimeric clusterin is a component of the chicken eggshell matrix and egg white. Matrix Biol., 22, 397-407.

Mann K., Macek B., Olsen J.V., 2006. Proteomic analysis of the acid-soluble organic matrix of the chicken calcified eggshell layer. Proteomics, 6, 3801-3810.

Mann K., Olsen J.V., Macek B., Gnad F., Mann M., 2007. Phosphoproteins of the chicken eggshell calcified layer. Proteomics, 7, 106-115.

Mongin P., 1978. Acid-base balance during eggshell formation. In: Respiratory function of birds, adult and embryonic. Piiper J. (Ed). Springer Verlag, Berlin, Allemagne, 247-259.

Mongin P., Sauveur B., 1979. The specific appetite of domestic fowl. In: Food intake regulation in Poutry, Boorman KN, Freeman B.M. (Eds). BPS Edinburgh, 171-189.

Nys Y., 1993. Regulation of 1,25 (OH)2D3, of osteocalcin and of intestinal and uterine calbindin in hens. In: Avian endocrinology. Sharp P.J. (Ed). Bristol, UK. J. Endocrinol. Limited, 345-357.

Nys Y., 2010. Structure et formation de l'œuf. In : Science et technologie de l'œuf et des ovoproduits, Nau F., Guérin-Dubiard C., Baron F., Thapon J.L. (Eds). Editions Tec et Doc Lavoisier, Paris, France, 1, chap 5, 161 249.

Nys Y., Zawadzki J., Gautron J., Mills A.D., 1991. Whitening of brown-shelled eggs: Mineral composition of uterine fluid and rate of protoporphyrin deposition. Poult. Sci., 70, 1236- 1245

Nys Y., Hincke M.T., Arias J.L., Garcia-Ruiz J.M., Solomon S.E., 1999. Avian eggshell mineralization. Poult. Avian Biol. Rev., 10, 143-166.

Nys Y., Gautron J., McKee M.D., GarciaRuiz J.M., Hincke M., 2001. Biochemical and functional characterization of eggshell matrix proteins in hens. World's Poult. Sci. J., 57:401413.

Nys Y., Gautron J., Garcia-Ruiz J.M., Hincke M.T., 2004. Avian eggshell mineralization: Biochemical and functional characteriza- 
tion of matrix proteins. C. R. Palevol, 3, 549562.

Panheleux M., Bain M., Fernandez M.S., Morales I., Gautron J., Arias J.L., Solomon S.E., Hincke M., Nys Y., 1999a. Organic matrix composition and ultrastructure of eggshell: A comparative study. Brit. Poult. Sci., 40, 240-252.

Panheleux M., Kalin O., Gautron J., Nys Y., 1999b. Features of eggshell formation in guinea fowl: Kinetics of shell deposition, uterine protein secretion and uterine histology. Brit. Poult. Sci., 40, 632-643.

Panheleux M., Nys Y., Williams J., Gautron J., Boldicke T., Hincke M.T., 2000. Extraction and quantification by elisa of eggshell organic matrix proteins (ovocleidin-17, ovalbumin, ovotransferrin) in shell from young and old hens. Poult. Sci., 79, 580-588.

Pines M., Knopov V., Bar A., 1994 Involvement of osteopontin in egg shell formation in the laying chicken. Matrix Biol., 14, 765-771.
Quintana C., Sandoz D., 1978. Coquille de l'oeuf de caille: Étude ultrastructurale et cristallographique. Calcif. Tissue Res., 25, 145-149.

Reyes-Grajeda J.P., Moreno A., Romero A. 2004. Crystal structure of ovocleidin-17, a major protein of the calcified gallus gallus eggshell, implications in the calcite mineral growth pattern. J. Biol. Chem., 279, 40876-40881.

Rodriguez-Navarro A., Garcia-Ruiz J.M. 2000. Model of textural development of layered crystal aggregates. Eur. J. Mineral., 12 609-614.

Rodriguez-Navarro A., Romanek C.S. 2002. Mineral fabrics analysis using a low-cost universal stage for X-ray diffractometry. Eur. J. Mineral., 14, 987-992.

Sauveur B., 1988. Reproduction des volailles et production d'œufs. INRA Editions, Paris, France, 470p.

Sauveur B., 1996. Photopériodisme et reproduction des oiseaux domestiques femelles INRA Prod. Anim., 9, 25-34.
Sauveur B., Mongin P., 1971. Comparative study of uterine fluid and egg albumen in shell gland of hen, Ann. Biol. Anim. Bioch. Biophys., 11, 213-224.

Shen X.Y., Belcher A.M., Hansma P.K., Stucky G.D., Morse D.E., 1997. Molecular cloning and characterization of lustrin a, a matrix protein from shell and pearl nacre of haliotis rufescens. J. Biol. Chem., 272, 3247232481 .

Solomon S.E., 1991. Egg and egg quality. Wolfe Publishing Ltd, London. Thompson B.K., Hamilton R.M.G. (Eds). Wolfe Publishing Ltd, Londres, UK, 149p.

Travel A., Nys Y., Lopes E., 2010. Facteurs physiologiques et environnementaux influençant la qualité de l'œuf. In : Numéro Spécial, Qualité de l'œuf. Nys Y. (Ed). Inra Prod. Anim., 23, 155-166.

Tyler C., 1964. Wihhelm von nathusius 1821-1899 on avian eggshells. University of Reading, England, UK, 104p.

\section{Résumé}

La coquille de l'œuf est une structure minérale parfaitement définie. Elle est déposée chaque jour en moins de 24 h dans un milieu acellulaire, le fluide utérin, sécrété par la partie distale de l'oviducte. La poule exporte une quantité considérable de calcium, et adapte à de nombreux niveaux son métabolisme calcique. La coquille résulte d'une croissance cristalline radiale de la calcite initiée sur des amas organiques présents en surface des membranes coquillières. Cette croissance se poursuit pour former une couche compacte dont les cristaux présentent progressivement une direction privilégiée du fait d'une compétition spatiale entre sites adjacents. Les propriétés mécaniques exceptionnelles de la coquille résultent de la quantité et de l'organisation cristallographique de ce biomatériau, elles-mêmes contrôlées par la matrice organique. Celle-ci est composée de nombreuses protéines spécifiques, uniquement synthétisées par l'utérus de la poule. La spécificité du profil électrophorétique du fluide utérin à un stade de formation de la coquille, le contrôle du polymorphe (calcite) et de la morphologie des cristaux in vitro par les protéines de ce milieu plaident en faveur de ce contrôle de la fabrication de la coquille par sa matrice protéique. Cette hypothèse est renforcée par les observations in vivo d'une association entre texture ou solidité de la coquille avec les teneurs en protéines de la matrice organiques ou avec la présence de polymorphisme simple nucléotidique de gènes codant ces protéines.

\section{Abstract}

\section{Eggshell ultrastructure, properties and the process of mineralization: involvement of organic matrix in the eggshell fabric}

The eggshell of the hen is a highly ordered and mineralized structure, which is sequentially deposited within an acellular milieu - the uterine fluid secreted by the distal oviduct. Each day, the hen exports a huge amount of calcium to form the eggshell and undergoes tremendous changes in its calcium metabolism. The eggshell results from spherulitic crystal growth of calcite initiated on organic aggregates on the surface of eggshell membranes, followed by competition between radial crystallites for space, resulting in a compact columnar biomineral. The exceptional mechanical properties associated with the well-defined eggshell ultrastructure and its texture arise from the control of crystal morphology and growth by the organic matrix, amongst them proteins specific to the uterus and eggshell (ovocleidins and ovocalyxins). The uterine fluid constituents varies at different stages of egg calcification, and alter the morphology of calcite crystals grown in vitro. Moreover, there is a relationship between levels of matrix proteins or their single nucleotide polymorphisms upon eggshell texture or mechanical properties. All these features point to the control of eggshell fabric by the organic matrix.

NYS Y., HINCKE M.-T., HERNANDEZ-HERNANDEZ A., RODRIGUEZ-NAVARRO A.-B., GOMEZ-MORALES J., JONCHËRE V., GARCIA-RUIZ J.-M., GAUTRON J., 2010. Structure, propriétés et minéralisation de la coquille de l'œuf: rôle de la matrice organique dans le contrôle de sa fabrication. Numéro Spécial, Qualité de l'œuf. Nys Y. (Ed). Inra Prod. Anim., $23,143-154$ 